\title{
LASER DOPPLER FLOWMETRY PERMANENT TEETH
}

\author{
Radka Cholakova \\ Department of Oral Surgery, Faculty of Dental Medicine, Medical University - \\ Plovdiv, Bulgaria.
}

\begin{abstract}
:
Laser Doppler Flowmetry (LDF) is a modern, noninvasive method used for examination of blood perfusion and microcirculation in dental pulp and gingiva, especially after trauma.

Purpose: The objective of this study is to determine in vivo the mean values of perfusion units in intact permanent teeth by LDF.

Material and methods: LDF was performed on symmetrical permanent teeth of both jaws. The study included 60 patients below 25 years of age, divided into two groups: first - with mixed dentition (7-9 years of age); second - with permanent dentition (18-25 years of age). Measurements were performed using the system moorVMS LDF2.
\end{abstract}

Results: The mean results of the LDF in maxilla are central (group 1-10.08 $\pm 3.08 \mathrm{PU}$; group $2-7.16 \pm 3.08$ PU) and lateral (group1 - 11.62 \pm 3.34 PU; group2 - $4.8 \pm$ $1.65 \mathrm{PU})$ incisor, canine $(6.76 \pm 2.55 \mathrm{PU})$, first $(6.98 \pm 2.7$ $\mathrm{PU})$ and second $(4.5 \pm 1.85 \mathrm{PU})$ premolars, respective in mandible: central (group 1- $8.6 \pm 1.28 \mathrm{PU}$; group 2 -9.61 $\pm 5.28 \mathrm{PU}$ ) and lateral incisor (group $1-9.82 \pm 1.77 \mathrm{PU}$; group $2-8.13 \pm 5.75 \mathrm{PU})$, canine $(6.31 \pm 3.73 \mathrm{PU})$, first $(8.06 \pm 3.93 \mathrm{PU})$ and second $(5.5 \pm 3.17 \mathrm{PU})$ premolars.

Conclusion: In order to detect changes in pulpal blood flow after trauma, it is recommended to use the contralateral tooth for comparison.

Keywords: laser Doppler flowmetry, permanent teeth, mature teeth, immature teeth,

\section{INTRODUCTION:}

The Doppler effect was described by the Austrian physicist and mathematician Christian Doppler (1803$1853)$ in 1842. In medicine, the Doppler effect is applied in vascular diagnostics. It is based on the fact that the difference between the frequencies of the emitted ultrasound wave and the ultrasound wave reflected by the red blood cells is proportional to the velocity of movement of the red blood cells. This information is processed by complex equipment, and interpretation of some parameters such as blood flow velocity, pulsatility index, peripheral resistance, etc. is possible. Laser Doppler Flowmetry (LDF) is a modern, non-invasive method for assessment of hemodynamics in tissues based on the Doppler effect, demonstrated in medical practice by Maiman in 1960. In dental medicine, laser Doppler measurements were first used by Gazelius et al. [1] in 1986. In modern dentistry, LDF is used for non-invasive examination of blood perfusion and microcirculation in dental pulp and gingiva, especially after trauma.

Laser Doppler devices emit monochromatic lowpower light which is scattered by the moving red blood cells, changing its frequency. This change is measured by the laser Doppler system. Two optical fibers are used - the first one delivers light to the tissues, and the second one detects the scattered light. The light detected by the laser Doppler system consists of two components: one component is the light scattered by the static tissue matrix, which is unchanged, and the other component is spectrally broadened as a result of its interaction with the moving red blood cells. Optical mixing of these components on the surface of the photodetector produces an electrical signal resulting in electrical voltage. It is directly proportional to the mean velocity of movement of the red blood cells and their concentration. The device detects the scattterd light and records the resulting signals or the "concentration and mean velocity of the cells" called Flux. It is defined as an arbitrary unit called perfusion unit (PU) [2, 3], as $2.5 \mathrm{~V}=250 \mathrm{PU}$.

\section{OBJECTIVE:}

The objective of this study is to determine in vivo the mean values of perfusion units in intact permanent teeth by laser Doppler flowmetry.

\section{MATERIAL AND METHODS:}

LDF was performed on symmetrical permanent teeth of both jaws. The study included 60 patients below 25 years of age, divided into two groups (Table 1): 
Table 1. Presents the inclusion and exclusion criteria for patients in both groups

\begin{tabular}{|c|c|c|}
\hline Group & Inclusion criteria & Exclusion criteria \\
\hline 1 & $\begin{array}{l}\text { 1. Children aged } 7 \text { to } 9 \text {. } \\
\text { 2. Intact, symmetrical teeth of the same type. } \\
\text { 3. Erupted permanent maxillary and mandibular } \\
\text { central and lateral incisors. } \\
\text { 4. Teeth with incomplete root development found } \\
\text { by radiography. } \\
\text { 5. Clinically healthy patients. }\end{array}$ & \multirow[t]{2}{*}{$\begin{array}{l}\text { 1. History of trauma in the last } 6 \text { months. } \\
\text { 2. Orthodontic treatment. } \\
\text { 3. Diseases of the jawbone. } \\
\text { 4. Molars of both jaws. } \\
\text { 5. Patients with cardiovascular diseases. } \\
\text { 6. Patients taking medications having effect on } \\
\text { the heart rate. }\end{array}$} \\
\hline 2 & $\begin{array}{l}\text { 1. Persons aged } 18 \text { to } 25 \text {. } \\
\text { 2. Intact, symmetrical teeth of the same type. } \\
\text { 3. Central and lateral incisors, canines, maxillary } \\
\text { and mandibular first and second premolars. } \\
\text { 4. Teeth with complete root development. } \\
\text { 5. Clinically healthy patients. }\end{array}$ & \\
\hline
\end{tabular}

- Group 1 - patients with mixed dentition (7-9 years of age);

- Group 2 - patients with permanent dentition (18-25 years of age).

Measurements were performed using the system moorVMS LDF2 (785 $\pm 10 \mathrm{~nm}$, maximum power 2.5mW) (Moor Instruments Ltd. Millwey Axminster Devon EX13 5HU, UK) (Fig. 1) and needle probes as per the manufacturer's instructions, and were processed by the use of specialized software (moor VMS-PC, V 3.1 for Vascular Monitor System).

Fig. 1. Laser Doppler flowmeter

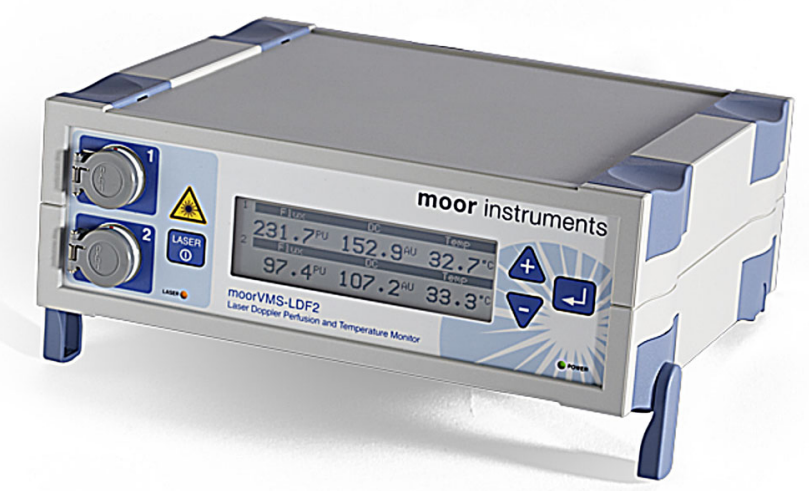

Patients were provided with individual silicone splints made of putty impression material (Zeta plus putty, Zhermack, Italy), covering the teeth between the two maxillary and mandibular second premolars in occlusion, and in the children - up to the canines. If the frontal coverage was deep, the impression was taken in occlusion in which upper and lower occlusal surfaces meet. In the vestibular aspect, the silicone splint was formed with a thickness of at least $3 \mathrm{~mm}$. Thus, a reliable fixation of the two probes placed perpendicularly in contact with the vestibular surfaces of the examined teeth was provided during the monitoring for a period of at least 3 minutes, together with providing a distance between the probes and the soft tissues in the oral cavity (gingivae, lips, cheeks). For each measurement, two needle probes were used - straight and angular (Fig. 2, 3), with a thickness of $1.5 \mathrm{~mm}$.
Fig. 2. Straight needle probe

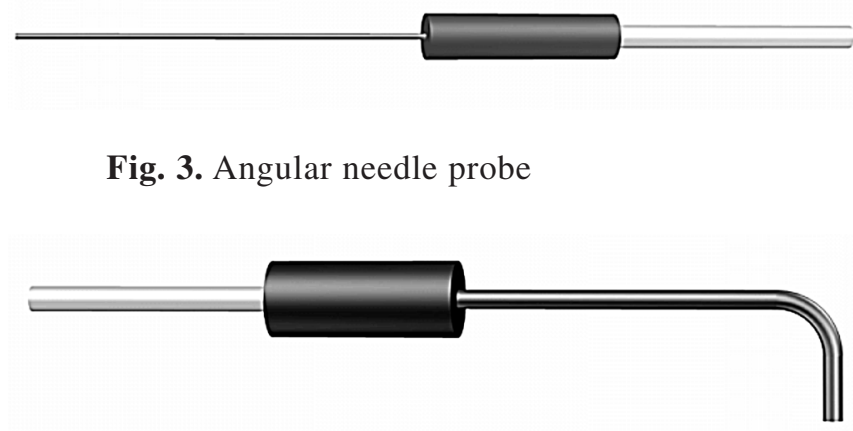

This was possible due to the specificity of the twochannel device allowing simultaneous monitoring and measurement of blood perfusion in two separate zones in the same period. The probes were fixed in the impression material at a perforation with a diameter of $1.5 \mathrm{~mm}$, which was placed at $3 \mathrm{~mm}$ above the gingiva so that to avoid microcirculation in it. Measurements were performed only in the presence of symmetrical intact teeth, with the straight probe placed on the left tooth of the jaw and the angular probe placed on the right tooth.

\section{RESULTS:}

The sex ratio in the first group was 2:1 in favour of males, and in the second group - 2.33:1 in favour of females. The mean results of the LDF performed are summarized in Table 2. Values of pulp perfusion in permanent teeth. 
Table 2. Values of pulp perfusion in permanent teeth

\begin{tabular}{|c|c|c|c|c|}
\hline \multirow{2}{*}{} & \multicolumn{2}{|c|}{ Maxilla } & \multicolumn{2}{c|}{ Mandible } \\
\cline { 2 - 5 } & Group 1 & Group 2 & Group 1 & Group 2 \\
\hline Central incisor & $10.08 \pm 3.08 \mathrm{PU}$ & $7.16 \pm 3.08 \mathrm{PU}$ & $8.6 \pm 1.28 \mathrm{PU}$ & $9.61 \pm 5.28 \mathrm{PU}$ \\
\hline Lateral incisor & $11.62 \pm 3.34 \mathrm{PU}$ & $4.8 \pm 1.65 \mathrm{PU}$ & $9.82 \pm 1.77 \mathrm{PU}$ & $8.13 \pm 5.75 \mathrm{PU}$ \\
\hline Canine & & $6.76 \pm 2.55 \mathrm{PU}$ & & $6.31 \pm 3.73 \mathrm{PU}$ \\
\hline First premolar & & $6.98 \pm 2.7 \mathrm{PU}$ & & $8.06 \pm 3.93 \mathrm{PU}$ \\
\hline Second premolar & & $4.5 \pm 1.85 \mathrm{PU}$ & & $5.5 \pm 3.17 \mathrm{PU}$ \\
\hline
\end{tabular}

\section{DISCUSSION:}

LDF is used to assess the vitality of traumatized teeth in dentistry. The tests available in the routine clinical practice determine the condition of the dental pulp by measuring its reaction to thermal or electrical stimuli. Since vitality of teeth depends on their vascularisation, and the above mentioned tests are based on the reaction of sensitive nerve terminals, they do not always provide reliable information about vitality of teeth [4]. Thus, teeth with incompletely formed roots or teeth which have temporarily lost their sensory function due to trauma will not respond to these tests, although they have retained their vascularisation [5]. Therefore, it is necessary to find blood perfusion values which give information on the processes in the pulp.

According to Norer et al., the individual comparisons of tooth morphotype-related pulpal blood flow values show significant interindividual differences for the lateral incisor, the canine, the premolars and the first molar. He found that pulpal blood flow values for the second premolar (11.1 PU) were significantly higher, and those for the central incisor (7.6 PU) were significantly lower than those for the lateral incisor (9.2 PU) and first molar (9.4 PU). The measurements at the lateral incisor, the first premolar and the first molar did not differ significantly [6]. As a reason for this, some authors point out the organization of the crystalline structure of enamel and dentin in teeth of different morphotype [7].

Multiple testing of the same tooth in a patient showed no statistically significant differences in pulpal blood flow values. Regarding the use of LFD as a method for measuring pulpal blood flow, the authors have found that contralateral teeth can be considered adequate controls in assessing the dental perfusion reference values in each patient. Differences in pulpal blood flow values for the same tooth in different patients are much greater than the differences in values between the left and the right tooth of the same type [6]. The means of pulpal blood flow values for the maxillary central incisor (7.6 PU) are similar to the values obtained in our study (7.16 PU), and those for the lateral incisor and the canine (9.2 PU and 8.2 PU, respectively) differ from our results (4.8 PU and 6.76 PU) and are inconsistent with those reported by other authors [7] who report mean pulpal blood flow values of approximately 14 PU for the central incisor, 5 PU for the lateral incisor, 3 to $14 \mathrm{PU}$ for the canine. However, the results of the assessment of pulpal blood flow cannot be compared due to differences in methodologies. In our study, the probe was placed at a distance of approximately $3 \mathrm{~mm}$ from the gingiva unlike the position used by other authors - "in the middle between the gingival margin and the orthodontic bracket" [7] or "the centre of the cervical third of the dental crown" [8]. In addition, the differences in characteristics of the LDF devices (wavelength and power output) can explain the inconsistency in the pulpal blood flow values associated with the tooth morphotype. Other studies use Periflux (Perimed) system with a wavelength $(632.8 \mathrm{~mm})$, which is different from the wavelength used in our study - moorVMS LDF2 (785 \pm $10 \mathrm{~nm})$. In addition, the higher power used in these studies $(2.5 \mathrm{~mW}$ vs. 1 and $2.0 \mathrm{~mW})$ may have resulted in significantly greater laser beam penetration, which influences the values obtained in the studies.

The results of LDF of the maxillary central and lateral incisors in the children group are $(11.31 \pm 2.21 \mathrm{PU})$ and (12.18 \pm 2.65 PU) [9] and (7.7 \pm 1.3 PU), which included teeth with incomplete root development [10]; our results are $(10.08 \pm 3.08 \mathrm{PU})$ and $(11.62 \pm 3.34 \mathrm{PU})$, respectively, and in persons in the 18-25 years of age group $(7.16 \pm 3.08 \mathrm{PU})$ and $(4.8 \pm 1.65 \mathrm{PU})$, respectively. The values in children are slightly lower in our study, and the results for the lateral incisors are slightly higher than those for the central incisors, probably due to the later eruption and closure of the apex of the lateral incisors. No statistically significant difference between left and right teeth was found. The results of some authors [9] show that the pulpal blood flow of the maxillary central incisor is greater than that of the lateral central incisor in the younger subjects, probably due to the fact that the pulp chamber is larger and contains more blood vessels. There is also evidence of a linear positive correlation between the pulpal blood flow values of the maxillary central and lateral incisors in young subjects, i.e. the increase in pulpal blood flow values of the lateral incisor is associated with increase in the pulpal blood flow values of the central incisor and vice versa. Unlike young subjects, the perfusion units of the lateral incisors in children are significantly higher than those of the central incisors [9]. This may be due to their early eruption and the closure of the apex in the same patient [11]. The results of this study 
show that the pulpal blood flow values of the maxillary incisors decrease as the age increases, and the pulpal blood flow values of the lateral incisors decrease faster than those of the central incisors. This may be due to the fact that the lateral incisors have smaller pulp chambers. In tooth root development, apical foramen diameter reduces, thus decreasing tooth vascularisation. Our study found increased pulpal perfusion in mandibular teeth compared to their corresponding maxillary teeth.

\section{CONCLUSION:}

Pulpal blood flow values obtained by LDF show great individual differences which are influenced by a number of factors: device parameters, method of fixation of the probes, isolation of the teeth from the gingival perfusion and the blood flow in the lips, cheeks and tongue. As the age increases, the values obtained by the use of the LDF decrease due to dental maturation, closure of the apical foramen and decrease in the pulp chamber volume as a result of secondary dentine deposition. In order to detect changes in pulpal blood flow after trauma, it is recommended to use the contralateral tooth for comparison, but because, in many cases, it is affected by the injury, the trend of the results over time can be observed, i. e. the increase in values obtained by the use of LFD indicates an increase in the circulation in the pulp.

\section{REFERENCES:}

1. Gazelius B, Olgart L, Edwall B, Edwall L. Non-invasive recording of blood flow in human dental pulp. Endod Dent Traumatol. 1986 Oct; 2(5):219-21.[PubMed]

2. Ghouth N, Duggal MS, Bani Hani A, Nazzal H. The diagnostic accuracy of laser Doppler flowmetry in assessing pulp blood flow in permanent teeth: A systematic review. Dent Traumatol. 2018; Oct;34(5):311-319. [PubMed] [Crossref]

3. Todea C, Canjau S, Miron M, Vitez B, Noditi G. Laser Doppler Flowmetry Evaluation of the Microcirculation in Dentistry. In: Microcirculation Revisited - From Molecules to Clinical Practice. by Lenasi H. (Editor). InTech. October 26, 2016. Chapter 9; pp.203-229. [Internet]

4. Abd-Elmeguid A, Yu DC. Dental pulp neurophysiology: part 2. Current diagnostic tests to assess pulp vi- tality. J Can Dent Assoc. 2009 Mar; 75(2):139-43. [PubMed]

5. Grga D, Dzeletovic B, Zivkovic S, Krsljak E. Blood flow measurement by laser doppler method in orofacial region. Serbian Dental Journal. 2010; 57(3):141-148 [Crossref]

6. Norer B, Kranewitter R, Emshoff R. Pulpal blood-flow characteristics of maxillary tooth morphotypes as assessed with laser Doppler flowmetry. Oral Surg Oral Med Oral Pathol Oral Radiol Endod. 1999 Jan; 87(1):88-92. [PubMed] [Crossref]

7. Ramsay DS, Artun J, Bloomquist D. Orthognathic surgery and pulpal blood flow: a pilot study using laser Doppler flowmetry. J Oral Maxillofac Surg. 1991 Jun;49(6):56470. [PubMed] [Crossref]

8. Ebihara A, Tokita Y, Izawa T, Suda H. Pulpal blood flow assessed by laser Doppler flowmetry in a tooth with a horizontal root fracture. Oral Surg Oral Med Oral Pathol Oral Radiol Endod. 1996 Feb;81(2):22933. [PubMed] [Crossref]

9. Ninghu M, Gang X, Yuanyuan Z, Lin Z, Shuyang H, Shanshan D, et al. [Study on using laser Doppler flowmetry to determine the pulpal blood flow of immature maxillary incisors]. [in Chinese] Ниа Xi Kou Qiang Yi Xue Za Zhi. 2017 Oct 1;35(5):494497. [PubMed] [Crossref]

10. Ersahan S, Sabuncuoglu FA, Oktay EA. The Efficacy of Laser Doppler Flowmetry, Electric Pulp Test and Cold Test in Diagnosing Revascularization of Extrusively Luxated Immature Maxillary Incisors. Pak J Med Sci. 2018 Jul-Aug;34(4):787-793. [PubMed] [Crossref]

11. Nolla CM. The development of permanent teeth. J Dent Child. 1960, 27:254-263. [Internet]

Please cite this article as: Cholakova R. Laser Doppler Flowmetry in permanent teeth. J of IMAB. 2019 OctDec;25(4):2751-2754. DOI: https://doi.org/10.5272/jimab.2019254.2751

\author{
Address for correspondence: \\ Dr. Radka Cholakova, \\ Department of Oral Surgery, Faculty of Dental Medicine, Medical University - \\ Plovdiv, Bulgaria \\ E-mail: r_cholakova1978@abv.bg
}

